\title{
Pemodelan Pola Produktivitas Cabai Rawit di Kabupaten Magelang*
}

\author{
Yohanes Purnama ${ }^{1}$, Farit M Afendi ${ }^{2 \ddagger}$, and Agus M Soleh ${ }^{3}$ \\ ${ }^{1,2,3}$ Department of Statistics, IPB University, Indonesia \\ ${ }^{\ddagger}$ corresponding author: fmafendi@apps.ipb.ac.id
}

Copyright (c) 2021 Yohanes Purnama, Farit M Afendi, and Agus M Soleh. This is an open-access article distributed under the Creative Commons Attribution License, which permits unrestricted use, distribution, and reproduction in any medium, provided the original work is properly cited.

\begin{abstract}
The objective of this study was to determine the best model that describe the pattern of cayenne pepper productivity in Magelang Regency. This study uses primary data which was obtained from the results of a survey of cayenne pepper production by the General Director of Horticulture on several sample plots in Magelang District, Central Java Province in 2018. The process of data analysis was divided into two parts: grouping the sample plots based on the similarity in productivity pattern and then fitting models in each group. The models used to fit data were Logistic Growth Model, Monomolecular Growth Model, Exponential Growth Model, Polynomial Model and Linear B-Spline Model. The best model was determined based on $R^{2}$ and MAPE. The results showed that the pattern of cayenne pepper productivity in Magelang District had eight different characteristics. Characteristics of each groups were illustrated by the similarity of their productivity pattern. The best model in each group was Linear B-Spline Model.
\end{abstract}

Keywords: cayenne pepper, linear B-Spline, productivity pattern.

\footnotetext{
*Received: Jul 2019; Reviewed: Des 2020; Published: Jan 2021
} 


\section{Pendahuluan}

Pertanian merupakan sektor yang sangat urgen dalam pembangunan perekonomian di Indonesia. Sumbangsih sektor pertanian dalam upaya peningkatan perekonomian negara cukup signifikan. Berdasarkan laporan tahunan Kementrian Pertanian tahun 2016, kontribusi sektor pertanian terhadap nilai produk domestik bruto (PDB) nasional untuk periode tahun 2014-2016 menunjukkan tren positif dari tahun ke tahun. Pada tahun 2016, kontribusi PDB sektor pertanian (di luar perikanan dan kehutanan) terhadap PDB nasional mencapai 10.21\% ([KEMENTAN], 2016). Hal tersebut kurang lebih mengkonfirmasi bahwa sektor ini memberikan sumbangsih positif terhadap pertumbuhan ekonomi nasional.

Salah satu sektor strategis dalam bidang pertanian adalah subsektor hortikultura. Subsektor hortikultura berperan penting dalam penyediaan produk kesehatan dan kosmetika, pangan, budaya dan parawisata, perdagangan, penciptaan PDB serta penyerapan tenaga kerja ([BPS\&DEPTAN], 2008). Dalam penciptaan PDB misalnya, subsektor hortikultura menyumbang sebesar $26.34 \%$ dari total sumbangan PDB sektor pertanian terhadap PDB nasional. Angka tersebut tentu cukup besar mengingat sektor pertanian yang memiliki subsektor yang cukup banyak. Oleh karena itu, maka subsektor hortikultura perlu mendapatkan perhatian dan penangan yang baik agar memperoleh hasil yang memuaskan.

Pada proses pengumpulan data hortikultura di lapangan, petugas seringkali mengalami kendala terutama untuk komoditas yang melakukan panen berulang seperti cabai. Metode yang digunakan untuk pengumpulan data cabai adalah melakukan pengukuran produksi yang dilakukan oleh petugas setiap kali panen. Para petugas di lapangan diharuskan untuk melakukan pengukuran secara berkala selama periode panen. Hal demikian tentu sangat menguras dana, tenaga dan waktu yang tidak sedikit. Selain itu, letak plot contoh yang cukup jauh dan sulit dijangkau juga menjadi kendala dalam proses pengukuran di lapangan ([DEPTAN], 2012).

Berangkat dari kondisi itu, muncul gagasan untuk menyederhanakan teknik pengumpulan data di lapangan dengan mengurangi frekuensi amatan dalam periode panen. Dalam penelitian ini akan dilakukan pemodelan pola produktivias cabai untuk menentukan model terbaik yang menggambarkan pola produktivitas cabai rawit di Kabupaten Magelang. Wijayanto et al. (2014) menyebutkan bahwa pada umumnya produksi tanaman hortikultura khususnya komoditas yang melakukan panen berulang membentuk pola nonlinier. Sehubungan dengan hal tersebut, maka beberapa model regresi seperti Model Kuadratik, Model Kubik, Model Pertumbuhan Monomolekular, Model Pertumbuhan Logistik, Model Pertumbuhan Eksponensial dan Model B-Spline Linier akan digunakan untuk membuat model pola produktivitas cabai. Model terbaik yang diperoleh nantinya digunakan untuk melakukan pendugaan produktivitas total dalam satu kabupaten.

\section{Regresi Nonlinier}

Secara umum Model Regresi Nonlinier dapat ditulis dalam bentuk (Venables \& Ripley, 2002):

$$
y_{i}=f\left(x_{i}, \beta\right)+\varepsilon_{i}, i=1,2, \ldots, n
$$


dengan $y$ adalah peubah respon, $x=$ peubah bebas, $f($.$) adalah fungsi regresi dengan$ parameter $\beta$ yang harus diduga dan $\varepsilon_{i}$ adalah galat. $\varepsilon_{i}$ diasumsikan saling bebas dan menyebar normal dengan nilai tengah nol dan ragam $\sigma^{2}$. Banyak model nonlinier yang telah didesain untuk situasi khusus, di antaranya adalah Model Pertumbuhan Logistik, Model Pertumbuhan Eksponensial dan Model Pertumbuhan Monomolekular.

a. Model Pertumbuhan Logistik

Menurut Nelder (1961), bentuk umum Model Pertumbuhan Logistik adalah:

$$
y_{i}=\frac{\theta_{1}}{1+\theta_{2} \times \exp \left(-\theta_{3} t_{i}\right)}+\varepsilon_{i}
$$

$\theta_{1}$ adalah limit bagi nilai $y$. Jika nilai $t=0$ maka $y=\frac{\theta_{1}}{1+\theta_{2}}$.

b. Model Pertumbuhan Eksponensial

Model Pertumbuhan Eksponensial merupakan contoh model nonlinier yang dapat ditransformasi ke bentuk linier. Bentuk umumnya (Hathout, 2013) adalah

$$
y_{i}=\beta_{0} e^{\beta_{1} t_{i}}+\varepsilon_{i}
$$

c. Model Perrtumbuhan Monomolekular

Bentuk umum Model Pertumbuhan Monomolekular (Koya \& Goshu, 2013) adalah:

$$
y_{i}=\theta_{1}\left(1-\theta_{2} \exp \left(-\theta_{3} t_{i}\right)\right)+\varepsilon_{i}
$$

\subsection{Model Polinomial}

Bentuk umum Model Polinomial adalah (Devore, 2014):

$$
y_{i}=\beta_{0}+\beta_{1} x_{i}+\beta_{2} x_{i}^{2}+\ldots+\beta_{n} x_{i}^{q}+\varepsilon_{i}
$$

dimana:

$$
\begin{aligned}
& y_{i}=\text { Nilai peubah respon } y \text { pada amatan ke- } i \\
& x_{i}=\text { Nilai peubah } x \text { untuk amatan yang ke- } i \\
& \beta=\text { Koefisien regresi } \\
& \varepsilon=\text { Galat }\left(\varepsilon \sim N\left(0, \sigma^{2}\right)\right)
\end{aligned}
$$

\subsection{Model B-Spline Linier}

B-spline merupakan model polinomial tersegmen pada suatu titik fokus yang disebut knot. Hal tersebut memberikan sifat fleksibilitas yang baik. Menurut Budiantara et al. $(2006)$, bentuk umum regresi nonparametrik B-spline berorde $m$ dengan $K$ knot $u_{1}, u_{2}, \ldots, u_{K}$ dinyatakan sebagai:

$$
y_{i}=\sum_{j=1}^{m+K} \beta_{j} B_{j-m, m}\left(x_{i}\right)+\varepsilon_{i}, i=1,2, \ldots, n
$$


$\beta_{j}$ adalah parameter model, $B_{j-m, m}$ adalah basis B-Spline ke- $j$ berorde $m$, dengan $m=$ $2,3,4$ dan $x_{i}$ adalah variabel bebas. $\varepsilon_{i}$ adalah sisaan ke- $i$.

Fungsi B-Spline secara rekursif didefinisikan sebagai:

$$
B_{j, m}(x)=\frac{x-K_{j}}{K_{j+m-1}-K_{j}} B_{j, m-1}(x)+\frac{K_{j+m}-x}{K_{j+m}-K_{j+1}} B_{j+1, m-1}(x)
$$

dengan

$$
B_{j, 1}(x)= \begin{cases}1, & x \in\left[k_{j}, k_{j+1}\right] \\ 0, & \text { Selainnya }\end{cases}
$$

Dalam membangun fungsi B-Spline berorde $m$, diperlukan tambahan knot sebanyak $2 m$. Koefisien $\beta_{j}$ dapat diduga dengan metode kuadrat terkecil yaitu:

$$
e^{2}=\sum_{i=1}^{n}\left(y_{i}-\hat{y}_{i}\right)^{2}
$$

sehingga diperoleh:

$$
\hat{\beta}=\left[B(x)^{\prime} B(x)\right]^{-1}\left[B(x)^{\prime} y\right]
$$

dengan $B(x)$ adalah matriks berukuran $n \times(m+K)$.

$$
B(x)=\left(\begin{array}{cccc}
B_{1-m, m}\left(x_{1}\right) & B_{2-m, m}\left(x_{1}\right) & \ldots & B_{K, m}\left(x_{1}\right) \\
B_{1-m, m}\left(x_{2}\right) & B_{2-m, m}\left(x_{2}\right) & \ldots & B_{K, m}\left(x_{2}\right) \\
\cdot & \cdot & \ldots & \cdot \\
\cdot & \cdot & \ldots & \cdot \\
\cdot & \cdot & \ldots & \cdot \\
B_{1-m, m}\left(x_{n}\right) & B_{2-m, m}\left(x_{n}\right) & \ldots & B_{K, m}\left(x_{n}\right)
\end{array}\right)
$$

\section{Pedugaan Parameter}

\subsection{Metode Kuadrat Terkecil Nonlinier}

Metode kuadrat terkecil dalam model regresi linier berbeda dengan metode kuadrat terkecil dalam model regresi nonlinier. Metode kuadrat terkecil nonlinier ditentukan dengan algoritma yang dapat memberikan jumlah kuadrat galat yang paling minimum.

Secara umum jika model nonlinier dapat ditransformasi ke dalam model linier maka semua rumus dan analisis teori regresi linier dapat digunakan pula. Tetapi jika tidak dapat ditransformasi ke dalam model linier maka cara yang digunakan adalah menuliskan persamaan normal secara rinci dan mengembangkan suatu teknik iteratif untuk memecahkannya. Metode kuadrat terkecil nonlinier (MKT nonlinier) merupakan pendugaan parameter yang dilakukan dengan cara meminimumkan jumlah kuadrat galatnya:

$$
S S E=\sum_{i=1}^{n}\left[y_{i}-f\left(x_{i}, \hat{\beta}\right)\right]^{2}
$$

Pada pendugaan dengan MKT nonlinier, nilai dugaan hanya dapat diselesaikan melalui proses iterasi. Beberapa metode yang digunakan dalam proses iterasi untuk MKT nonlinier adalah metode Gauss-Newton dan metode Marquardt-Levenberg. 


\subsection{Metode Gauss-Newton}

Salah satu metode yang digunakan untuk menduga parameter dalam model regresi nonlinier adalah Metode Gauss-Newton. Dalam proses iterasi untuk menduga parameter, metode ini membutuhkan nilai awal. Nilai-nilai awal tersebut menjadi acuan dalam proses iterasi sehingga pemilihan nilai awal yang tepat akan berdampak pada lama tidaknya proses iterasi yang dilakukan untuk memperoleh parameter-parameter yang meminimumkan jumlah kuadrat galat dari model. Misalkan $\beta_{0}=\left(\beta_{10}, \beta_{20}, \ldots, \beta_{p 0}\right)$ adalah vektor nilai dugaan awal. Model $y_{i}=f\left(x_{i}, \beta\right)+\varepsilon_{i}$ diuraikan menjadi deret Taylor di sekitar $\beta=\beta_{0}$ dan hanya mempertahankan bentuk linier, sehingga:

$$
f\left(x_{i}, \beta\right) \cong f\left(x_{i}, \beta_{0}\right)+\sum_{j=1}^{p}\left[\frac{\partial f\left(x_{i}, \beta\right)}{\partial \beta_{j}}\right]_{\beta=\beta_{0}}\left(\beta_{j}-\beta_{j 0}\right)(i=1,2, \ldots, n)
$$

Persamaan di atas dapat dinyatakan dalam bentuk model linier yaitu sebagai berikut:

$$
f\left(x_{i}, \beta\right)-f\left(x_{i}, \beta_{0}\right) \cong \gamma_{1} W_{1 i}+\gamma_{2} W_{2 i}+\ldots+\gamma_{j} W_{j i}
$$

dimana $W_{j i}=\left[\frac{\partial f\left(x_{i}, \beta\right)}{\partial \beta_{j}}\right]$ adalah turunan dari model nonlinier terhadap parameter ke-j pada semua nilai awal dan $\gamma_{j}=\beta_{j}-\beta_{j 0}$. Sisi kiri persamaan (2) sebagai sisaan $y_{i}-f\left(x_{i}, \beta_{0}\right)$ dan parameter diganti oleh nilai awal. Pada model linier, $W_{j i}$ berperan sebagai peubah penjelas dan $\gamma_{j}$ berperan sebagai koefisien model. Hasilnya prosedur Gauss-Newton mempunyai struktur regresi linier, yaitu:

$$
y_{i}-f\left(x_{i}, \beta_{0}\right) \cong \gamma_{1} W_{1 i}+\gamma_{2} W_{2 i}+\ldots+\gamma_{j} W_{j i}
$$

Nilai dugaan setiap parameter dicari dengan melakukan proses iteratif berikut:

1. Duga $\gamma_{1}, \gamma_{2}, \ldots, \gamma_{p}$ dalam model (3) dengan menggunakan MKT linier. Penduga dari iterasi pertama dinyatakan sebagai $\hat{\gamma}_{11}, \hat{\gamma}_{21}, \ldots, \hat{\gamma}_{p 1}$.

2. Hitung $\hat{\beta}_{j 1}=\beta_{j 0}+\hat{\gamma}_{j 1}$ dengan $(j=1,2, \ldots, p)$. $\hat{\beta}_{11}, \hat{\beta}_{21}, \ldots, \hat{\beta}_{j 1}$ adalah nilai dugaan iterasi pertama.

3. Nilai $\hat{\beta}$ dari langkah 2 menjadi nilai awal model (3).

4. Kembali ke langkah 1, kemudian hitung $\hat{\gamma}_{11}, \hat{\gamma}_{21}, \ldots, \hat{\gamma}_{p 1}$ dan $\hat{\beta}_{12}, \hat{\beta}_{22}, \ldots, \hat{\beta}_{j 2}$.

5. Proses ini terus dilakukan sampai konvergen. Konvergen tercapai apabila dalam $s$ iterasi, jumlah kuadrat sisaan dan penduga parameter tidak lagi berubah nilainya.

Pada setiap iterasi, $\hat{\gamma}_{j}$ merupakan kenaikan yang ditambahkan kepada penduga dari iterasi sebelumnya seperti dalam langkah 2. Vektor penduga pada iterasi ke-s terkait dengan iterasi ke- $s+1$, secara formal dapat dinyatakan sebagai berikut

$$
\hat{\beta}_{s+1}=\hat{\beta}_{s}+\left(W_{s}^{\prime} W_{s}\right)^{-1} W_{s}^{\prime} e_{s}
$$

dimana $W_{s}$ adalah matriks berukuran $n \times p$ dengan unsur $(i, j)$ adalah $\left[\frac{\partial f\left(x_{i}, \beta_{0}\right)}{\partial \beta_{j}}\right]_{\beta=\beta_{s}}$ dan $e_{s}$ adalah vektor sisaan.

\subsection{Prosedur Marquardt-Levenberg}

Prosedur Marquardt-Levenberg merupakan pengembangan dari prosedur Gauss-Newton yang digunakan untuk menghitung vektor perubahan kenaikan. Struktur dari vektor 
kenaikan untuk iterasi ke- $s$ adalah solusi $\hat{\gamma}_{s}$ tehadap persamaan:

$$
\left(W_{s}^{\prime} W_{s}+\lambda I_{p}\right)_{\gamma_{s}}=W_{s}^{\prime} f\left[y-f\left(\hat{\beta}_{s}\right)\right]
$$

dengan nilai $\lambda>0$. Marquardt menyatakan bahwa $\lambda$ dapat memperbaiki kekonvergenan. Nilai $\lambda$ dapat menangani situasi ketika pangkat matriks $\mathrm{W}$ tak penuh dan matriks $W^{\prime} W$ menjadi singular.

Pemilihan $\lambda$ dalam prosedur Marquardt-Levenberg disesuaikan pada masing-masing iterasi untuk meyakinkan pengurangan sisaan. Jika nilai $\lambda$ dimulai dengan nilai besar, prosedur Marquardt-Levenberg merubah langkah $\hat{\gamma}$ dekat arah turunan tercuram. Jika nilai $\lambda$ kecil, prosedur Marquardt-Levenberg mendekati prosedur Gauss-Newton. Nilai $\lambda$ dikendalikan dengan cara dinaikan atau diturunkan jika satu tahap gagal untuk mengurangi sisaan. Dengan cara ini prosedur Marquardt-Levenberg mampu menyesuaikan diri dengan cara mendekati turunan tercuram ketika jauh dari sisaan yang minimum dan cepat konvergen ketika di sekitar sisaan yang minimum.

\subsection{Evaluasi Model}

Kriteria yang digunakan dalam pemilihan model terbaik adalah nilai koefisien determinasi $\left(R^{2}\right)$ dan Mean Absolute Percentage Error (MAPE).

a. Koefisien Determinasi

Koefisien determinasi merupakan ukuran keragaman peubah respon yang mampu diterangkan oleh model. Formulanya adalah:

$$
R^{2}=\frac{J K R}{J K T}
$$

dimana

$\mathrm{JKR}=$ Jumlah kuadrat regresi

$\mathrm{JKT}=$ Jumlah kuadrat total

Semakin besar $R^{2}$ suatu model maka semakin terandalkan model tersebut.

b. MAPE

Persamannya adalah:

$$
M A P E=\frac{100}{n} \sum_{i=1}^{n}\left|\frac{y_{i}-\hat{y}_{i}}{y_{i}}\right|
$$

dengan

$y_{i}=$ Nilai aktual

$\hat{y}_{i}=$ Nilai dugaan

$n=$ Banyak amatan

Semakin kecil nilai MAPE berarti bahwa model semakin baik.

\section{Metodologi}

\subsection{Data}

Data yang digunakan dalam penelitian ini merupakan data primer. Data primer diperoleh dari hasil survei produksi cabai rawit oleh Dirjen Hortikultura pada beberapa plot contoh yang dipanen pada tahun 2018 di Kabupaten Magelang, Provinsi Jawa 
Tengah. Plot contoh yang menjadi sampel adalah lahan dari lima belas petani champion yang merupakan petani maju yang dikordinasikan oleh Kementerian Pertanian Bersama Dinas Pertanian untuk menjadi lokomotif penggerak bagi petani lain di daerahnya.

\subsection{Metode Penelitian}

Analisis data yang dilakukan pada penelitian ini dibagi menjadi 2 tahap yaitu:

Tahap I: Eksplorasi data

Eksplorasi data dilakukan untuk memperoleh gambaran data secara umum. Proses yang dikerjakan pada tahap ini adalah membuat statistik deskriptif untuk melihat rangkuman informasi yang penting dari data serta membuat plot untuk melihat pola produktivitas dari masing-masing plot contoh. Bagian akhir dari tahap ini adalah mengelompokan nilai-nilai produktivitas seluruh plot contoh berdasarkan kemiripan pola produktivitasnya.

Tahap II: Identifikasi model

Model pola produktivitas dibangun berdasarkan pola produktivitas yang telah dikelompokan pada tahap I. Model yang dicobakan antara lain, Model Pertumbuhan Logistik, Model Pertumbuhan Eksponensial, Model Pertumbuhan Monomolekular, Model Kuadratik, Model Kubik, dan Model B-Spline Linier. Pemilihan model terbaik dilakukan berdasarkan nilai $R^{2}$ dan MAPE.

\section{Hasil dan Pembahasan}

\subsection{Eksplorasi Data}

Secara umum, plot contoh yang diamati di Kabupaten Magelang memiliki frekuensi panen sebanyak 17 kali. Jenis cabai yang ditanam petani adalah Cabai Rawit. Range produktivitas berkisar antara 0.54-5.20 ton/ha dengan rata-rata 2.19 ton/ha. Di sisi lain, luas panen berkisar antara 0.1-0.2 ha. Sebagian besar petani memiliki luas panen sebesar 0.1 ha.

Gambaran pola produktivitas cabai rawit masing-masing kelompok dapat dilihat pada Gambar 1 sampai Gambar 8. Kedelapan kelompok tersebut merupakan hasil analisis gerombol dengan mempertimbangkan kemiripan pola roduktivitasnya. Penggerombolan dilakukan dengan metode penggerombolan Time Series dengan jarak DTW (Dynamic Time Warping). Hal yang menarik bahwa pola produktivitas cabai rawit antar kelompok cukup bervariasi. Selain itu, nilai produktivitas pada beberapa kelompok terlihat cukup besar dibandingkan kelompok lainnya. Hal ini dapat dilihat pada kelompok 3, 4 dan 7 .

Pola produktivitas cabai pada kelompok 1 (Gambar 1) terlihat berfluktuasi pada periode tertentu dalam masa panen. Namun, pola produktivitasnya memiliki tren naik sampai akhir panen. Selain itu, umumnya puncak produktivitas cabai terjadi pada panen ke-8. Hanya satu plot saja yang puncak produktivitasnya pada panen terakhir yaitu plot 14. Gambaran pola produktivitas pada kelompok 2 (Gambar 2) terlihat perlahan naik sampai titik tertentu, kemudian turun perlahan sampai panen habis. Puncak produktivitas terjadi pada panen ke-8 sampai panen ke-11. Puncak produktivitas cabai kelompok 3 (Gambar 3) adalah pada panen ke-12. Pada akhir panen, produktivitasnya terlihat naik kembali tetapi tidak sampai sebesar pada puncak produktivitasnya. Pada Gambar 4, pola produktivitas cabai naik pada awal panen. Puncak produktivitas pada panen ke-5. Setelah itu, produktivitas perlahan menurun. 
Tabel 1: Nilai $R^{2}$ dan MAPE setiap model pada masing-masing kelompok.

\begin{tabular}{|c|c|c|c|}
\hline Kelompok & Model & $R^{2}$ & MAPE \\
\hline \multirow[t]{6}{*}{1} & Eksponensial & 0.41 & 0.36 \\
\hline & Logistik & 0.61 & 0.21 \\
\hline & Monomolekular & 0.47 & 0.31 \\
\hline & Kuadratik & 0.59 & 0.22 \\
\hline & Kubik & 0.61 & 0.21 \\
\hline & B-Spline Linier & 0.65 & 0.21 \\
\hline \multirow[t]{6}{*}{2} & Eksponensial & 0.05 & 0.71 \\
\hline & Logistik & 0.34 & 0.36 \\
\hline & Monomolekular & 0.07 & 0.68 \\
\hline & Kuadratik & 0.41 & 0.39 \\
\hline & Kubik & 0.42 & 0.36 \\
\hline & B-Spline Linier & 0.44 & 0.35 \\
\hline \multirow[t]{6}{*}{3} & Eksponensial & 0.35 & 1.08 \\
\hline & Logistik & 0.73 & 0.28 \\
\hline & Monomolekular & 0.51 & 0.62 \\
\hline & Kuadratik & 0.79 & 0.46 \\
\hline & Kubik & 0.83 & 0.26 \\
\hline & B-Spline Linier & 0.86 & 0.29 \\
\hline \multirow[t]{6}{*}{4} & Eksponensial & 0.15 & 0.67 \\
\hline & Logistik & 0.17 & 0.65 \\
\hline & Monomolekular & 0.15 & 0.67 \\
\hline & Kuadratik & 0.16 & 0.66 \\
\hline & Kubik & 0.59 & 0.35 \\
\hline & B-Spline Linier & 0.73 & 0.27 \\
\hline \multirow[t]{6}{*}{5} & Eksponensial & 0.01 & 1.18 \\
\hline & Logistik & 0.22 & 0.68 \\
\hline & Monomolekularl & 0.01 & 1.18 \\
\hline & Kuadratik & 0.39 & 0.71 \\
\hline & Kubik & 0.47 & 0.54 \\
\hline & B-Spline Linier & 0.49 & 0.601 \\
\hline \multirow[t]{6}{*}{6} & Eksponensial & 0.73 & 0.46 \\
\hline & Logistik & 0.73 & 0.46 \\
\hline & Monomolekular & 0.50 & 0.70 \\
\hline & Kuadratik & 0.89 & 0.24 \\
\hline & Kubik & 0.90 & 0.24 \\
\hline & B-Spline Linier & 0.98 & 0.10 \\
\hline \multirow[t]{6}{*}{7} & Eksponensial & 0.06 & 0.30 \\
\hline & Logistik & 0.28 & 0.19 \\
\hline & Monomolekular & 0.07 & 0.30 \\
\hline & Kuadratik & 0.25 & 0.27 \\
\hline & Kubik & 0.45 & 0.19 \\
\hline & B-Spline Linier & 0.89 & 0.08 \\
\hline \multirow[t]{6}{*}{8} & Eksponensial & 0.01 & 0.89 \\
\hline & Logistik & 0.23 & 0.69 \\
\hline & Monomolekular & 0.02 & 0.88 \\
\hline & Kuadratik & 0.63 & 0.37 \\
\hline & Kubik & 0.70 & 0.37 \\
\hline & B-Spline Linier & 0.76 & 0.32 \\
\hline
\end{tabular}




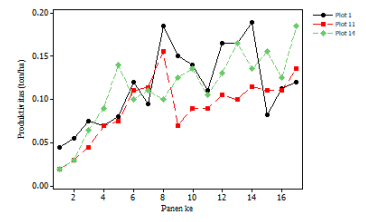

(a) Pola produktivitas kelompok 1

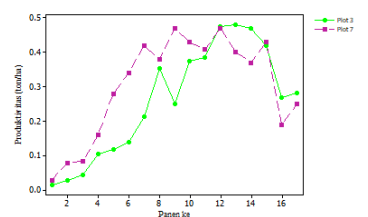

(c) Pola produktivitas kelompok 3

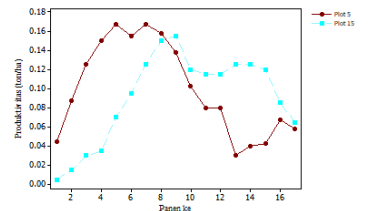

(e) Pola produktivitas kelompok 5

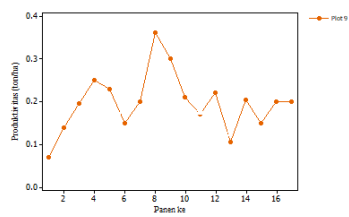

(g) Pola produktivitas kelompok 7

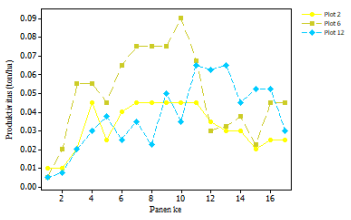

(b) Pola produktivitas kelompok 2

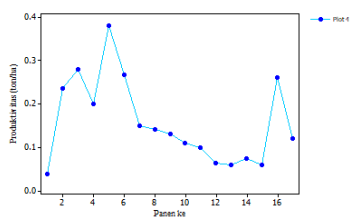

(d) Pola produktivitas kelompok 4

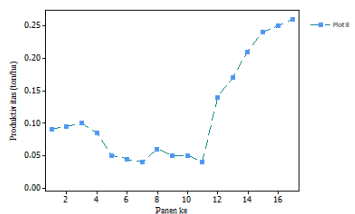

(f) Pola produktivitas kelompok 6

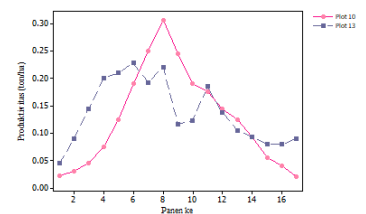

(h) Pola produktivitas kelompok 8

Pada panen ke-16, produktivitas terlihat kembali naik dan kemudian turun lagi pada akhir panen.

Pola produktivitas cabai pada kelompok 5 (Gambar 5) terlihat berangsur-angsur naik pada awal panen sampai pada titik tertentu. Puncak produktivitas pada panen ke-7 dan ke-9. Setelah itu, produktivitas mengalami penurunan sampai akhir panen. Visualisasi pola produktivitas cabai pada kelompok 6 (Gambar 6) terlihat sangat berbeda dari kelompok-kelompok yang lain. Pada awal panen produktivitas cabai teru mengalami kenaikan sampai panen ke-3. Kemudian, produktivitasnya menurun hingga panen ke-11. Produktivitas meningkat tajam mulai panen ke-12 sampai akhir panen. Pola produktivitas pada plot ini terlihat seperti kurva terbalik dan membentuk pola kuadratik. Informasi mengenai pola produktivitas cabai pada Gambar 7 menunjukkan bahwa produktivitas terus berfluktuasi dari panen ke panen. Pada awal panen produktivitas cabai terlihat naik sampai panen ke-4. Setelah itu, produktivitasnya menurun hingga panen ke-6. Produktivitas meningkat kembali mulai panen ke-7 sampai puncak panen yaitu panen ke-8. Kemudian, pola produktivitas terlihat terus berfluktuasi sampai akhir panen. Pola produktivitas cabai pada kelompok 8 (Gambar 8) terlihat seperti parabola terbuka ke bawah. Produktivitas cabai terus meningkat mulai awal panen sampai pada titik puncak yaitu pada panen ke-6 dan ke-8. Setelah itu, produktivitas turun secara perlahan sampai akhir panen. Pada plot 13, pola produktivitas terlihat masih berfluktuasi sampai lima periode panen setelah mencapai titik puncak. Namun, selanjutnya terus menurun sampai akhir panen. 


\subsection{Identifikasi Model}

Hasil identifikasi model untuk masing-masing kelompok dapat dilihat pada Tabel 1. Model terbaik pada setiap kelompok adalah model B-Spline Linier. Hal ini mengacu pada nilai $R^{2}$ dan MAPE yang diperoleh. Berikut ini adalah model terbaik yang menggambarkan pola produktivitas pada masing-masing kelompok.

a. Model pola produktivitas kelompok 1

$$
\hat{y}=0.028 B_{-1,2}(x)+0.185 B_{0,2}(x)+0.0692 B_{1,2}(x)+0.112 B_{2,2}(x)+0.1004 B_{3,2}(x)
$$

degan knot sebanyak $3\left(K_{1}=7.99, K_{2}=11.4712, K_{3}=12.1056\right)$.

b. Model pola produktivitas kelompok 2

$$
\hat{y}=0.0044 B_{-1,2}(x)+0.0329 B_{0,2}(x)+0.0519 B_{1,2}(x)+0.0263 B_{2,2}(x)
$$

degan knot sebanyak $2\left(K_{1}=3.6354, K_{2}=9.6706\right.$. $)$

c. Model pola produktivitas kelompok 3

$$
\hat{y}=0.004 B_{-1,2}(x)+0.376 B_{0,2}(x)+0.4679 B_{1,2}(x)+0.2163 B_{2,2}(x)+0.2712 B_{3,2}(x)
$$

degan knot sebanyak $3\left(K_{1}=8.3115, K_{2}=14.9135, K_{3}=15.486\right)$.

d. Model pola produktivitas kelompok 4

$$
\hat{y}=0.098 B_{-1,2}(x)+0.2653 B_{0,2}(x)+0.0579 B_{1,2}(x)-0.043 B_{2,2}(x)+0.081 B_{3,2}(x)
$$

degan knot sebanyak $3\left(K_{1}=5.1144, K_{2}=7, K_{3}=13.298\right)$.

e. Model pola produktivitas kelompok 5

$$
\hat{y}=0.0304 B_{-1,2}(x)+0.1196 B_{0,2}(x)+0.0266 B_{1,2}(x)
$$

degan knot $(K=6.844)$.

f. Model pola produktivitas kelompok 6

$$
\hat{y}=0.1042 B_{-1,2}(x)+0.0534 B_{0,2}(x)-0.0581 B_{1,2}(x)+0.0618 B_{2,2}(x)+0.1657 B_{3,2}(x)
$$

degan knot sebanyak $3\left(K_{1}=6, K_{2}=10.99, K_{3}=12.278\right)$.

g. Model pola produktivitas kelompok 7

$\hat{y}=0.07 B_{-1,2}(x)+0.20 B_{0,2}(x)+0.04 B_{1,2}(x)+0.30 B_{2,2}(x)+0.14 B_{3,2}(x)+0.07 B_{4,2}(x)+0.13 B_{5,2}(x)$

degan knot sebanyak $4\left(K_{1}=4.4091, K_{2}=6.454, K_{3}=8.11, K_{4}=12.278\right)$.

h. Model pola produktivitas kelompok 8

$$
\hat{y}=0.032 B_{-1,2}(x)+0.235 B_{0,2}(x)+0.1634 B_{1,2}(x)+0.0133 B_{2,2}(x)
$$

degan knot sebanyak $2\left(K_{1}=7.982, K_{2}=8.548\right)$.

\section{Simpulan}

Pola produktivitas cabai rawit di Kabupaten Magelang memiliki delapan karakteristik yang berbeda. Karakteristik masing-masing kelompok tergambar dari kemiripan pola produktivitasnya. Model terbaik yang menggambarkan pola produktivitas pada setiap kelompok adalah Model B-Spline Linier. Hal ini ditentukan berdasarkan performa nilai $R^{2}$ dan MAPE yang diperoleh. 


\section{Daftar Pustaka}

[BPS\&DEPTAN] (2008). Buku Pedoman Pengumpulan Data Hortikultura. Jakarta (ID): Badan Pusat Statistik dan Departemen Pertanian.

Budiantara, I. N., Suryadi, F., Otok, B. W., \& Guritno, S. (2006). Pemodelan B-Spline dan MARS pada nilai ujian masuk terhadap ipk mahasiswa jurusan disain komunikasi visual uk. Petra Surabaya. Teknik Industri, 8(1): 1-13.

[DEPTAN] (2012). Buku Pedoman Pengumpulan Data Tanaman Pangan dan Hortikultura. Jakarta (ID): Departemen Pertanian.

Devore, J. L. (2014). Probability and Statistics for Engineering and the Sciences. Edisi ke-9. US: Cengage Learning.

Hathout, D. (2013). Modeling population growth: Exponential and hyperbolic modeling. Applied Mathematics, 4(2): 299-304.

[KEMENTAN] (2016). Laporan Tahunan Kementrian Pertanian. Jakarta (ID): Kementerian Pertanian.

Koya, R. P. \& Goshu, T. A. (2013). Solutions of rate-state equation describing biological growths. American Journal of Mathematics and Statistics, 3(6): 305-311.

Nelder, J. (1961). The fitting of a generalization of the logistic curve. Biometrics, 17(1): 89-110.

Venables, B. \& Ripley, B. (2002). Modern Applied Statistics with S. Edisi ke-4. Springer.

Wijayanto, H., Sumertajaya, I. M., Fitrianto, A., \& Wahyuni, S. (2014). Statistical models for chili productivity. Applied Mathematical Sciences, 4(20): 69-79. 